\title{
Process Design of Micro-Arc Oxidation Coatings Based on Magnesium Lithium Alloy and Their Characteristics
}

\author{
Shuo-Jen Lee ${ }^{1}$, Le-Hung-Toan Do ${ }^{1, *}$, Jeou-Long Lee ${ }^{2}$, Huan-Chih Peng ${ }^{1}$ \\ ${ }^{1}$ Department of Mechanical Engineering, Yuan Ze University, Chung-Li, Taiwan 32003, R.O.C. \\ 2 Department of Chemical and Material Engineering, Lunghwa University of Science and Technology, \\ Guishan, Taoyuan County 33306, Taiwan, R.O.C. \\ *E-mail: toandlh@gmail.com, s1028705@mail.yzu.edu.tw
}

doi: 10.20964/2017.12.64

Received: 6 September 2017 / Accepted: 20 October 2017 / Published: 12 November 2017

\begin{abstract}
Micro-arc oxidation processes have several advantages and a high ability to be applied for corrosion protection to magnesium lithium alloys. The present study investigates the process design of micro-arc oxidation coated on an LZ91 magnesium alloy in an alkaline electrolyte. Coating thickness $\left(\mathrm{t}_{\mathrm{a}}\right)$, corrosion resistance $\left(\mathrm{R}_{\mathrm{p}}\right)$ and coating uniformity $\left(\mathrm{t}_{\mathrm{u}}\right)$ are utilized as indices for surface characteristics. The salient effects of the three key process parameters: current density, coating time and electrical frequency, on surface characteristics are identified with the use of the Taguchi method and optimal analysis. The relationship between the coating thickness and the uniformity of the coating is established to control the MAO coating process. The major factor affecting the corrosion resistance of the coatings is the current density. The results show that the predicted values for coating thickness $\left(\mathrm{t}_{\mathrm{a}}\right)$ and corrosion resistance $\left(\mathrm{R}_{\mathrm{p}}\right)$ are in close agreement with confirmation experimental results. Therefore, the surface characteristics of MAO coated LZ91 could be designed through the Taguchi design of experimentation and related optimal analyses.
\end{abstract}

Keywords: micro-arc oxidation (MAO), Taguchi method, coating thickness, corrosion resistance

\section{FULL TEXT}

(C) 2017 The Authors. Published by ESG (www.electrochemsci.org). This article is an open access article distributed under the terms and conditions of the Creative Commons Attribution license (http://creativecommons.org/licenses/by/4.0/). 